\title{
ЧЕЛОВЕЧЕСКИЙ КАПИТАЛ, КАК ЭЛЕМЕНТ РАЗВИТИЯ СТРАТЕГИЧЕСКОГО ПЛАНИРОВАНИЯ В РФ (НАЦИОНАЛЬНЫЕ ПРОЕКТЫ «КУЛЬТУРА», «БЕЗОПАСНЫЕ И КАЧЕСТВЕННЫЕ АВТОМОБИЛЬНЫЕ ДОРОГИ", «ЖИЛЬЕ И ГОРОДСКАЯ СРЕДА», «ЭКОЛОГИЯ», «НАУКА»)
}

\author{
(c) 2021 Петров А.M.
}

доктор экономических наук, профессор Департамента бизнес-аналитики Финансовый университет при Правительстве Российской Федерации, Россия, Москва

E-mail: palmi@inbox.ru

Государственное стратегическое планирование, являясь составной частью государственного стратегического управления, представляет собой ключевой инструмент модернизации функционирующей системы государственного управления. Человеческий капитал, как этап развития стратегического планирования в РФ, в статье рассмотрен на основе ряда национальных проектов.

Ключевые слова: человеческий капитал, культура, безопасные и качественные автомобильные дороги, жилье и городская среда, экология, наука, государственное стратегическое планирование.

Национальный проект «Культура» включает в себя 3 федеральных проекта, представленных на рисунке 1, направленных на повышение доступа к культуре, культурному самовыражению, образованию в культуре.

Культура является средством повышения осведомленности широкой общественности, подвергая сомнению стереотипы и коллективное восприятие, формируя философские размышления среди населения и создавая примеры инициатив. Культура расширяет кругозор, обеспечивает точку опоры для контактов и диалога между людьми различных культур, поднимает моральный дух людей. Примечательно, что культура впервые вошла в число основных направлений, развитие которых призвано ускорить социально-экономическое развитие РФ.

Для того, чтобы «сделать события в сфере культуры более доступными для людей в разных уголках нашей страны» был разработан ФП «Цифровая культура» [3], реализация которого позволит использовать искусство и творчество для создания чувства гордости за культуру нашей страны и для поощрения людей идти по пути образования и развития своих навыков и способностей.

Первым достижением реализации ФП «Цифровая культура» является запуск Всероссийского виртуального концертного зала и цифрового гида по экспозициям российских музеев Artefact.

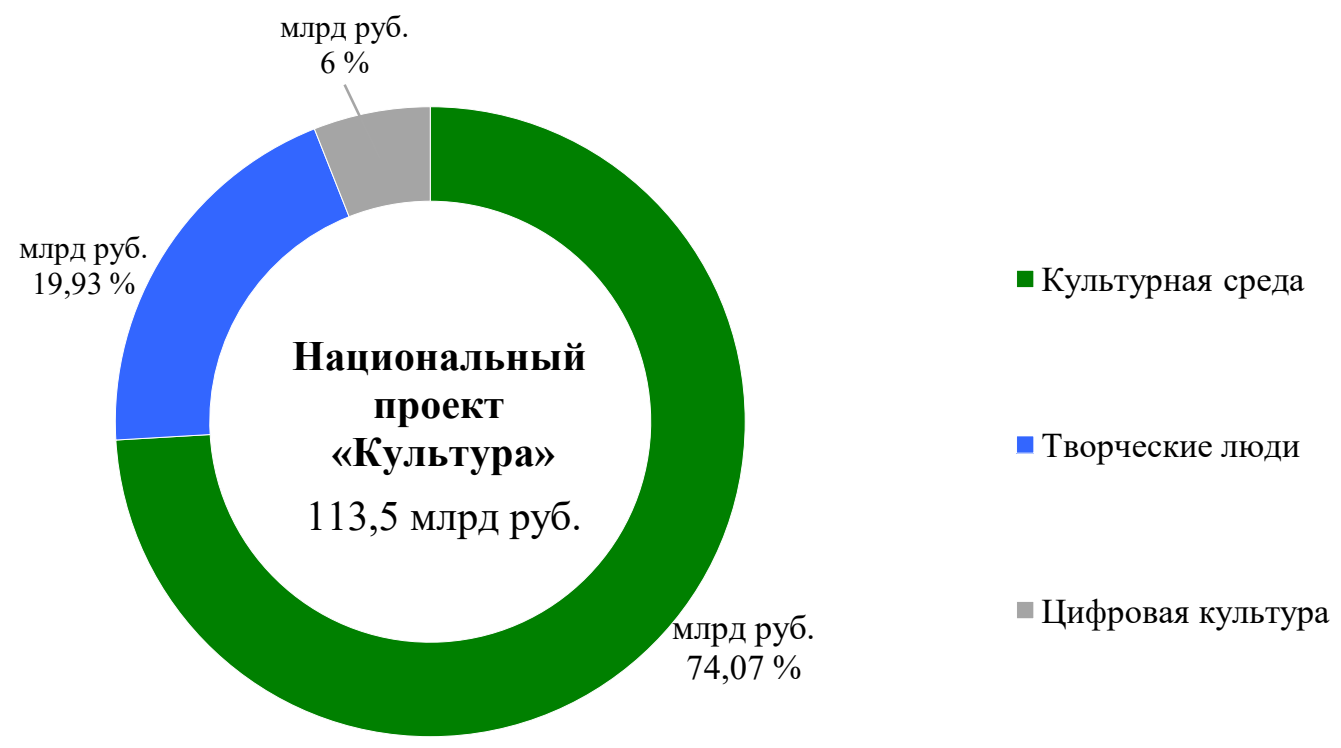

Рисунок 1. Общий объем финансирования федеральных проектов, входящих в состав национального проекта «Культура» 
Национальный проект «Безопасные и качественные автомобильные дороги» объединяет 4 федеральных проекта, представленных на рисунке 2, направленных на обеспечение безопасности каждого участника дорожного движения и предотвращение несчастных случаев.

Данные Доклада о состоянии безопасности дорожного движения в мире (Global status report on road safety 2018), подготовленного ВОЗ при финансовой поддержке Благотворительного фонда Bloomberg Philanthropies, свидетельствуют о продолжающемся росте смертности в результате дорожно-транспортных происшествий (далее - ДТП), достигнув к декабрю 2018 г. от- метки в 1,35 млн. чел. в год, что, как отмечает генеральный директор ВО3 Tedros Adhanom Ghebreyesus, является «недопустимой платой за мобильность» (рисунок 3) [4].

Официальный сайт Госавтоинспекции использует интерактивную карту, наглядно отражающую динамику ДТП в каждом из субъектов РФ для привлечения внимания к данной проблеме. При наведении на тот или иной субъект РФ всплывает информация, отражающая абсолютное значение показателей ДТП, количества погибших и раненых людей, а также темпа прироста данных показателей в сравнении с аналогичным периодом прошлого года.

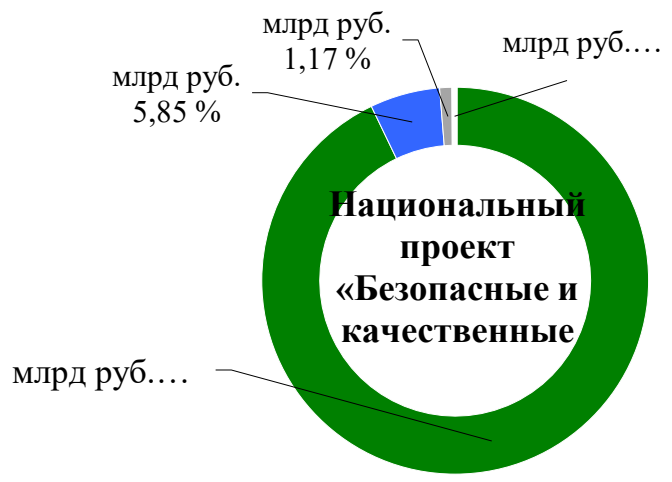

- Дорожная сеть

- Общесистемные меры развития дорожного хозяйства

- Безопасность дорожного движения

- Автомобильные дороги Минобороны России

Рисунок 2. Общий объем финансирования федеральных проектов, входящих в состав национального проекта «Безопасные и качественные автомобильные дороги»

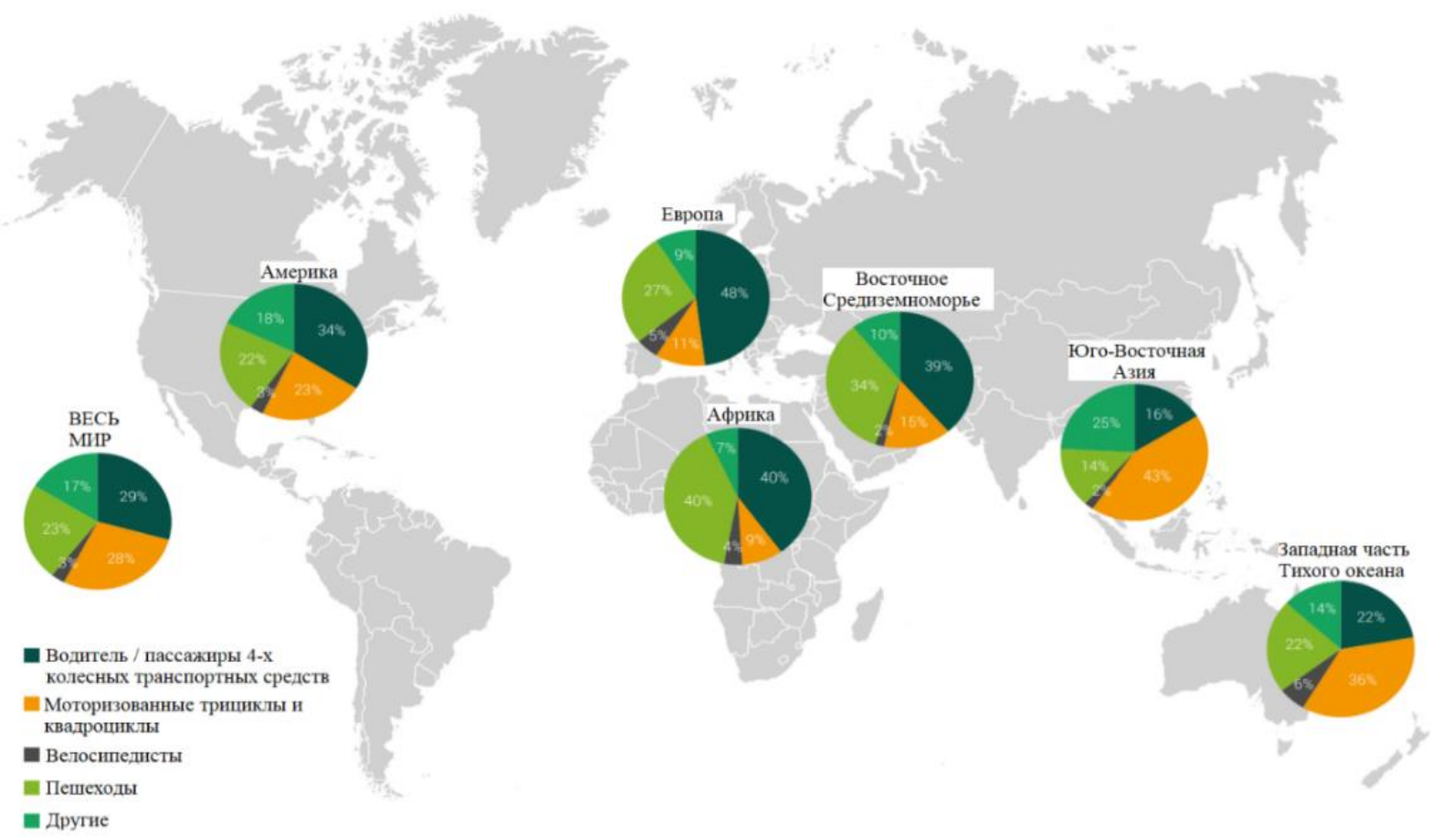

Рисунок 3. Распределение смертей по типам пользователей дорог 
Ситуация в сфере дорожного движения РФ имеет положительную динамику: за январьсентябрь 2019 г. на 3,2\% снизилось количество ДТП, на 13,5\% - количество погибших человек, на $2,2 \%$ - количество человек, пострадавших в ходе ДТП, по сравнению с аналогичным периодом прошлого года [7]. Вместе с тем до достижения стратегической цели НП «Безопасные и качественные автомобильные дороги» по снижению смертности на дорогах в 3 раза еще далеко.

НП «Жилье и городская среда», включающий 4 федеральных проекта, представленные на рисунке 4, ориентирован на достижение целевых показателей, представленных на рисунке 5.

По данным исследования ВЦИОМ 2019 г., представленным на рисунке 6, об удовлетворённости россиян качеством жилищнокоммунальных услуг (далее - ЖКУ) наблюдается увеличение количества людей, вполне удовлетворенных качеством ЖКУ, однако их доля невелика (22\% удовлетворённых) в сравнении с долей людей, неудовлетворенных в той или иной степени качеством ЖКУ.

Необходимо отметить, что в условиях пандемии были снижены ипотечные ставки до 6,5\%. Такое снижение должно было способствовать оживлению строительной отрасли и поддержать в затруднительных условиях население РФ.

НП «Экология» объединяет 11 федеральных проектов, представленных на рисунке 7, направленных на реализацию превентивных мер по

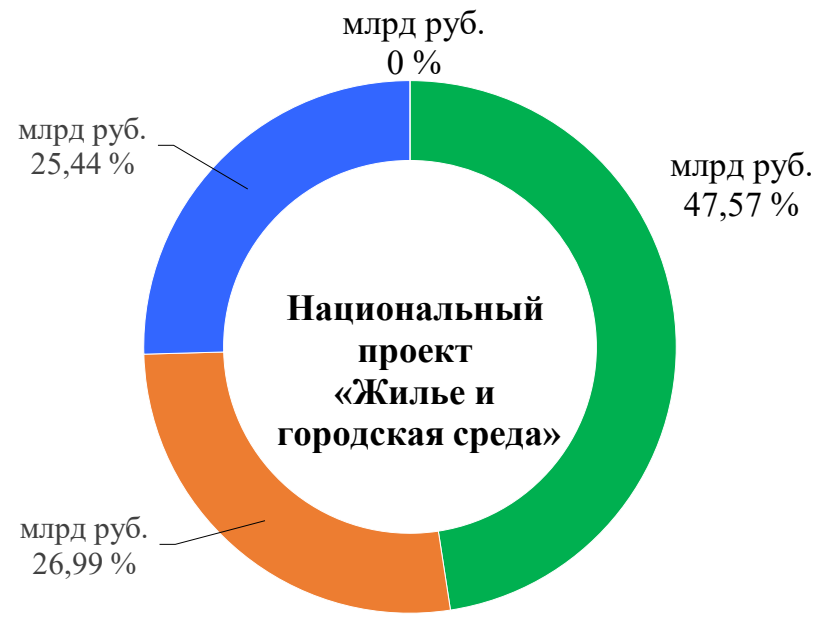

Ш Обеспечение устойчивого сокращения непригодного для проживания жилищного фонда

- Формирование комфортной городской среды

—илье

- Ипотека

Рисунок 4. Общий объем финансирования федеральных проектов, входящих в состав национального проекта «Жилье и городская среда»

Обеспечение доступным жильем семей со средним достатком, в том числе создание возможностей для приобретения (строительства ими жилья с использованием ипотечного кредита, ставка по которому должна быть менее $8 \%$ )
Увеличение объема жилищного строительства не менее чем до 120 млн м² в год
Кардинальное повышение комфортности городской среды, повышение индекса качества городской среды на $30 \%$, сокращение в соответствии с этим индексом количества городов с неблагоприятной средой в 2 раза

Целевые показатели ПН «жилье и городская среда»

Создание механизма прямого участия

граждан в формировании комфортной городской среды, увеличение доли граждан, принимающих участие в решении вопросов развития городской среды, до $30 \%$
Обеспечение устойчивого сокращения непригодного для проживания жилищного фонда 


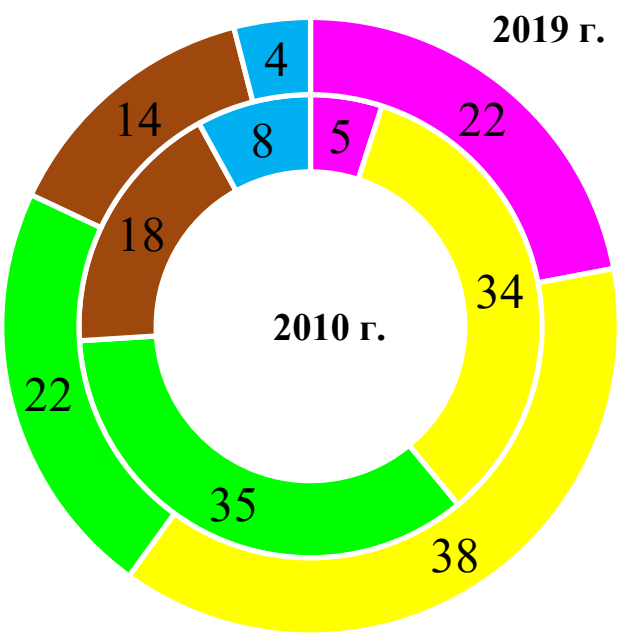

- Вполне удовлетворен

Скорее удовлетворен

- Скорее неудовлетворен

- Совершенно неудовлетворен

- Затрудняюсь ответить

Рисунок 6. Оценка удовлетворенности качеством ЖКУ в 2019 г. при возможности выбора 1 ответа, в \% от всех опрошенных

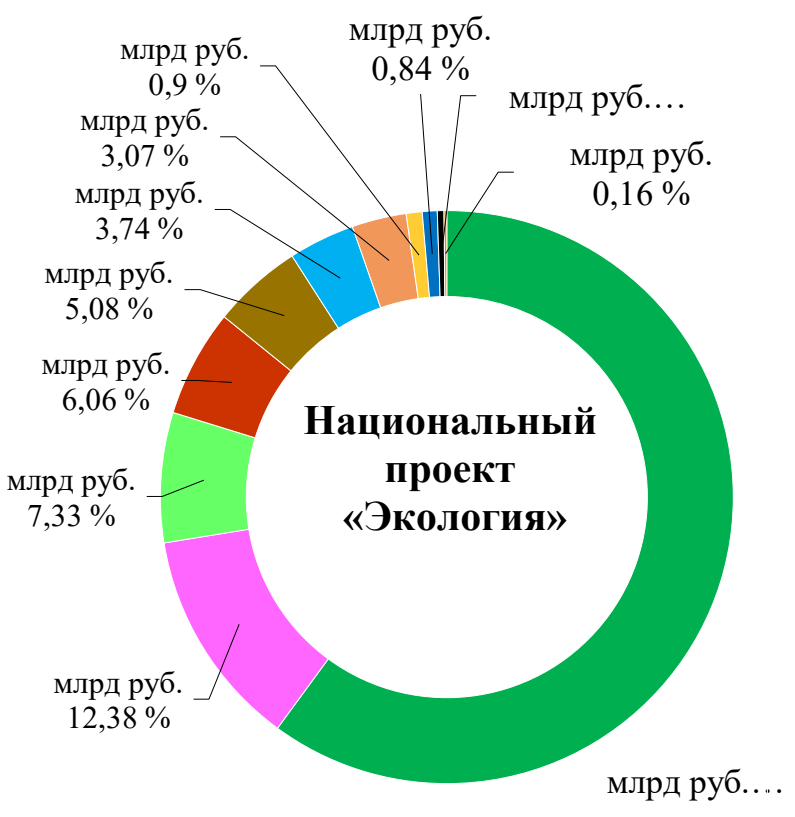

• Внедрение наилучших доступных технологий

- Чистый воздух

Комплексная система обращения с твердыми коммунальными отходами

- Чистая вода

- Оздоровление Волги

- Сохранение лесов

- Чистая страна

Инфраструктура для обращения с отходами I-II классов опасности

- Сохранение озера Байкал

- Сохранение уникальных водных объектов

- Сохранение биологического разнообразия и развитие экологического туризма

Рисунок 7. Общий объем финансирования федеральных проектов, входящих в состав национального проекта «Экология»

уменьшению негативного воздействия на состояние окружающей среды в максимально возможной и наиболее эффективной форме, чтобы каждый человек мог жить в благоприятной для здоровья среде.

ФП «Чистая вода» направлен на обеспечение качественной питьевой водой населения РФ. По данным исследования ВЦИОМ о качестве воды 2019 г. сохранилась на уровне 2016 г. доля россиян, пьющих только бутилированную воду $-16 \%$, $35 \%$ россиян пьют воду из крана благодаря использованию фильтров для воды.
Примечательно, что среди причин, названных в качестве основных причин, из-за которых люди не пьют воду из крана, представленных на рисунке 8, увеличилось с 1\% (2016 г.) до 20\% (2019 г.) количество людей, выбирающих ответ «все вышеперечисленные ответы» [12].

Ухудшение качества водных ресурсов при одновременном увеличении спроса на воду приводит к усилению конкуренции между потребителями водных ресурсов, вызывая необходимость постановки целевых показателей реализации данного ФП, представленных на рисунке 9. 


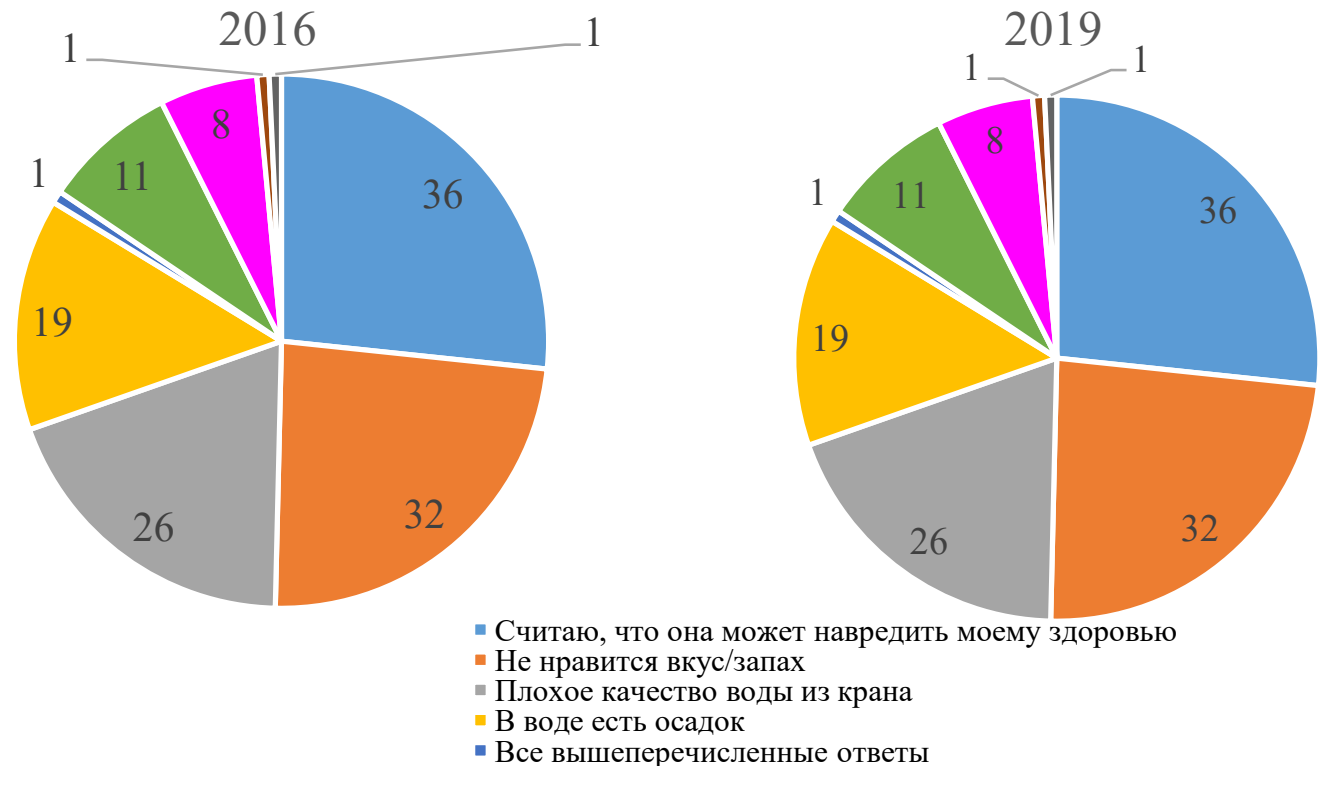

Рисунок 8. Оценка качества воды по данным опроса ВЦИОМ в 2019 г. при возможности выбора не более 2 ответов, в \% от непьющих воду из крана

ПРPEКTHЫЕ ПОКАЗАТЕЛИ:

Доля населения РФ, обеспеченного качественной питьевой водой из систем централизованного водоснабжения, \%

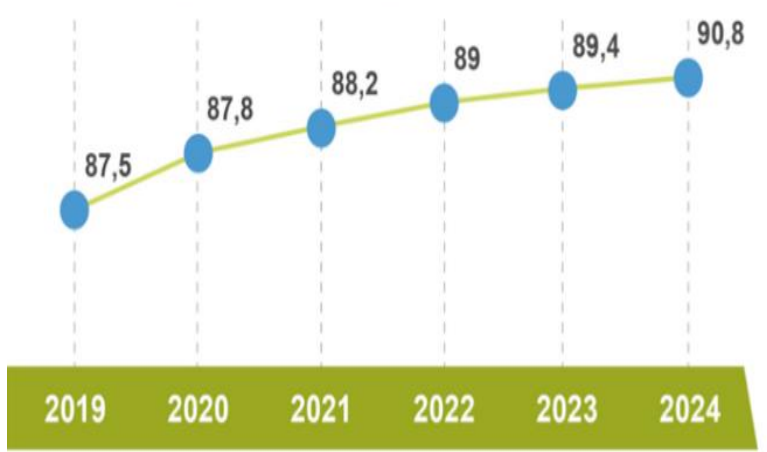

Доля городского населения РФ, обеспеченного качественной питьевой водой из систем централизованного водоснабжения, \%

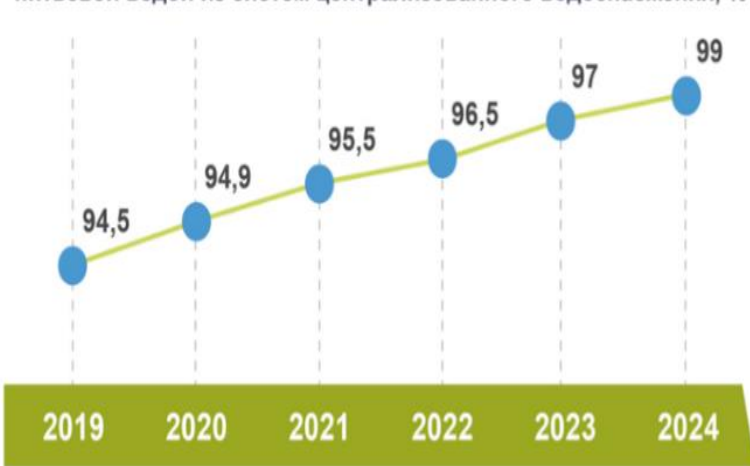

Рисунок 9. Целевые показатели ФП «Чистая вода» 
Вместе с тем необходимо понимать, что невозможно достичь данных целей усилиями одного государства, необходимо скоординированное управление международными водными бассейнами, в том числе за счет трансграничного сотрудничества. Данная идея нашла поддержку на международном уровне посредством реализации Инициативы по комплексному мониторингу Цели устойчивого развития 6, реализуемой в рамках механизма «ООН - водные ресурсы». Трансграничное водное сотрудничество имеет стратегическое значение в реализации Повестки дня в области устойчивого развития на период до 2030 года, принятой государствамичленами ООН в 2015 г. [14], поскольку 153 страны обладают общими трансграничными реками, озерами и водоносными горизонтами [15]. В этой связи особую актуальность приобретают ФП «Оздоровление Волги» и ФП «Сохранение озера Байкал».

НП «Наука» включает 3 федеральных проекта, представленных на рисунке 10 , задачи по реализации, которых представлены на рисунке 11. Как отметил М. Эскиндаров, при реализации НП «Наука» «важным направлением является восстановление в Российском государстве и обществе позиций Академии наук, развитие потенциала академических институтов» [16].

Граждане Российской Федерации, разделяя мнение Д.А.Медведева о том, что именно наука должна дать ответ на ряд вопросов о прорывных направлениях [16], в исследовании, проведенном ВЦИОМ в 2020 г., высказались за то, что наука является условием прогресса (49\% опрошенных) и источником полезных открытий (44\% опрошенных), что наглядно представлено на рисунке 12.

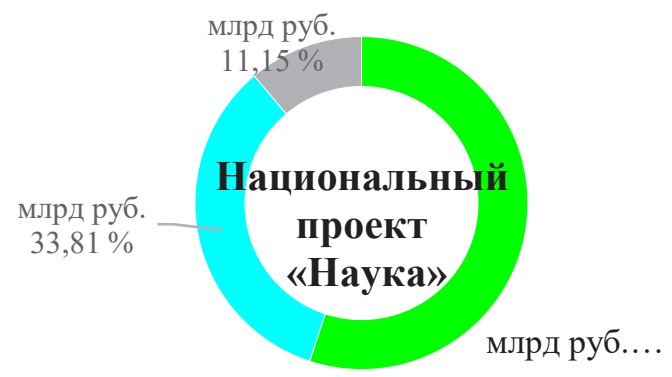

- Развитие передовой инфраструктуры для проведения исследований и разработок в Российской Федерации

- Развитие научной и научно-производственной кооперации

Рисунок 10. Общий объем финансирования федеральных проектов, входящих в состав НП »Наука»
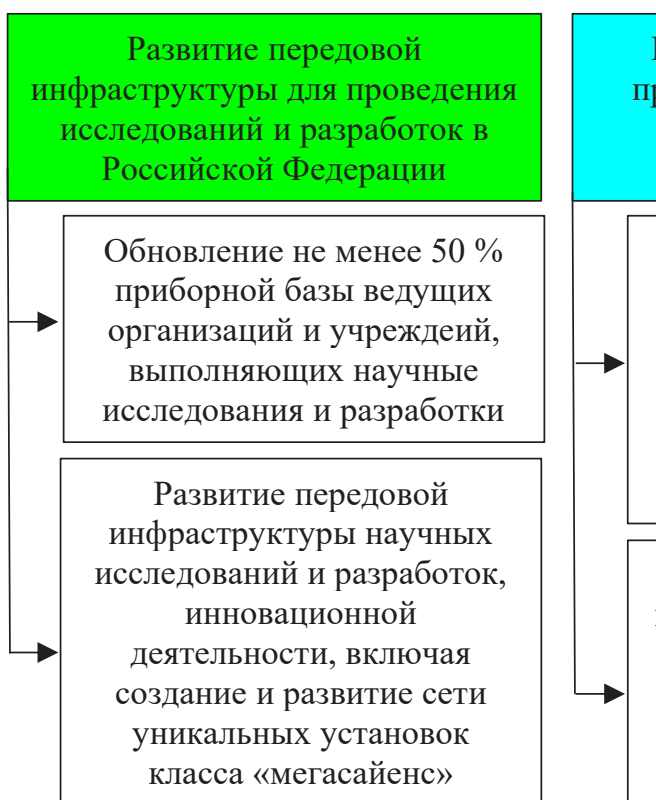

Развитие научной и научнопроизводственной кооперации

Создание не менее 15 научнообразовательных центров мирового уровня на основе интеграции университетов и научных организаций и их кооперации с организациями реального сектора экономики

Создание научных центров мирового уровня, включая сеть международных математических центров и центров геномных исследований
Развитие кадрового потенциала в сфере исследований и разработок

Формирование целостной системы подготовки и профессионального роста научных и научнопедагогических кадров, обеспечивающей условия для осуществления молодыми учеными научных исследований и разработок, создания научных лабораторий и конкурентоспособных коллективов

Рисунок 11. Задачи по реализации федеральных проектов, входящих в состав НП «Наука» 


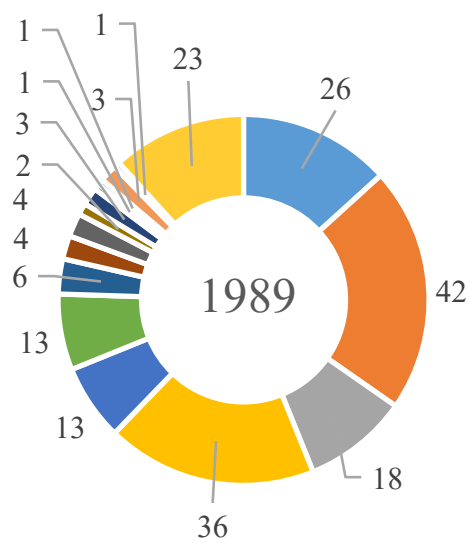

42
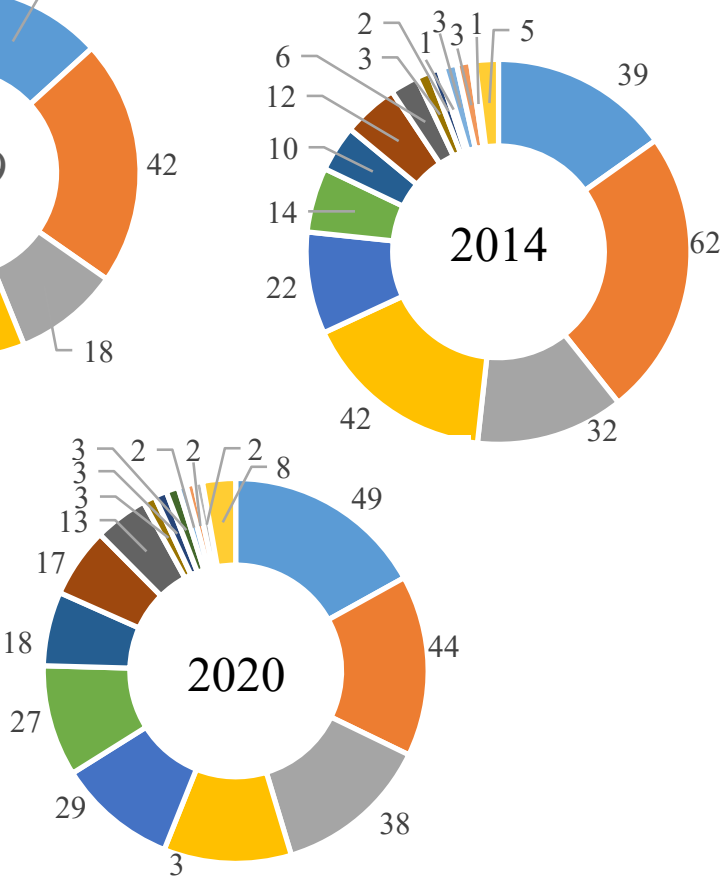

обществе

- Бескорыстное служение

- Гибельная сила

- Пустая трата средств

- Разрушение веры, красоты, нравственности

- Ложные идеалы

- Пустая говорильня

- Другое

- Затрудняюсь ответить

\section{Рисунок 12. Оценка места науки в жизни людей и общества по данным опроса ВЦИОМ при возможности выбора неограниченного числа ответов, в \% от всех опрошенных}

\section{Библиографический список}

1. Национальный проект «Культура» // Будущее России. Национальные проекты: [сайт].- Текст: электронный. - URL: https://futurerussia.gov.ru/kultura.

2. Национальный проект «Безопасные и качественные автомобильные дороги» // Будущее России. Национальные проекты: [сайт].- Текст: электронный.- URL: https://futurerussia.gov.ru/bezopasnye-i-kachestvennyeavtomobilnye-dorogi.

3. Медведев: нацпроект «Культура» должен сделать культурные события доступными по всей России // ТАСС: [сайт]. - 2019.- 17 апреля.- Текст: электронный. - URL: https://tass.ru/nacionalnye-proekty/6343659.

4. At Stockholm road safety summit, UN officials join global call to end 'scourge' of preventable deaths // United Nations News: [сайт]. - 2020. - 19 февраля.-Текст: электронный._URL: https://news.un.org/en/story/2020/02 /1057721.

5. Global status report on road safety 2018 // World Health Organization: [сайт].- Текст: электронный. - URL: https://www.who.int/publications-detail/global-status-report-on-road-safety-2018.

6. Картограмма // Официальный сайт Госавтоинспекции.- Текст: электронный. - URL: http://stat.gibdd.ru/.

7. На 13,5\% снизилась смертность в результате ДТП на подведомственных Росавтодору трассах // Федеральное дорожное агентство Росавтодор: [сайт].- 2019.- 17 октября.- Текст: электронный.- URL: https:// rosavtodor.ru/press-center/news/293571.

8. Национальный проект «Жилье и городская среда» // Будущее России. Национальные проекты: [сайт].Текст: электронный.-URL: https://futurerussia.gov.ru/zhile-i-gorodskaya-sreda.

9. Информационные материалы о национальном проекте «Жильё и городская среда» // Официальный сайт Правительства Российской Федерации.- Текст: электронный.- URL: http://static.government.ru/media/ files/ fPs8qW8PjyNAAKRWDTk7Ac9KdUhBcETX.pdf. 
10. Россияне о качестве ЖКХ // Всероссийский центр изучения общественного мнения: [сайт].-2019.- 03 июля. - Текст: электронный. - URL: https://wciom.ru/index.php?id=236\&uid=9786.

11. Национальный проект «Экология» // Будущее России. Национальные проекты: [сайт].- Текст: электронный.- URL: https://futurerussia.gov.ru/ekologiya.

12. Вода из-под крана: фильтруем и пьем // Всероссийский центр изучения общественного мнения: [сайт].2019. - 23 сентября. - Текст: электронный. - URL: https://wciom.ru/index.php?id=236\&uid=9914.

13. Global status report on road safety 2018 // World Health Organization: [сайт].- Текст: электронный.- URL: https://www.who.int/publications-detail/global-status-report-on-road-safety-2018.

14. Повестка дня в области устойчивого развития // ООН: [сайт].- Текст: электронный.- URL: https://www. un.org/sustainabledevelopment/ ru/about/development-agenda/.

15. Прогресс в области трансграничного водного сотрудничества: Глобальный базисный уровень для показателя 6.5.2 ЦУР 2018 // ЮНЕСКО: [сайт]. - 2018. - 04 сентября.- Текст: электронный._URL: http://ru.unesco. kz/progress-on-transboundary-water-cooperation.

16. Не ростом, так умом. Как национальные проекты повлияют на динамику российской экономики// Российская газета: [сайт].- 2019.- 14 мая.- Текст: электронный.- URL: https://rg.ru/2019/05/14/kak-nacionalnyeproekty-povliiaiut-na-dinamiku-rossijskoj-ekonomiki.html.

17. Национальный проект «Наука» // Будущее России. Национальные проекты: [сайт].- Текст: электронный.URL: https://futurerussia.gov.ru/nauka.

18. Паспорт национального проекта «Наука» (утв. президиумом Совета при Президенте РФ по стратегическому развитию и национальным проектам, протокол от 24.12.2018 № 16) // Справочно-правовая система «Консультант Плюс».- Текст: электронный.-URL: http://www.consultant.ru/document/cons_doc_LAW_319304/.

19. Медведев обсудил с президентом РАН роль ученых в выполнении поручений из послания Путина // ТАСС: [сайт]. - 2018.- 23 марта.- Текст: электронный._URL: https://nauka.tass.ru/nauka/5058875.

20. Россия - страна технооптимистов // Всероссийский центр изучения общественного мнения: [сайт].2019. - 05 февраля.- Текст: электронный. - URL: https://wciom.ru/index.php?id=236\&uid=10151.

21. Chernysheva N.A., Perskaya V. V., Petrov A. M., Bakulina A.A. GREEN ENERGY FOR BELT AND ROAD INITIATIVE: ECONOMIC ASPECTS TODAY AND IN THE FUTURE / International Journal of Energy Economics and Policy. 2019. T. 9. № 5. C. 178-185.

22. Kevorkova Z.A., Petrov A. M., Savina N. V. TOWARDS LIABILITIES OF CORPORATE SYSTEMS / International Journal of Civil Engineering and Technology. 2019. T. 10. № 2. C. 1582-1593.

23. Petrov A.M., Nikiforova E. V., Kiseleva N.P., Grishkina S. N., Lihtarova O. V. CREATION OF THE REPORTING ON SUSTAINABLE DEVELOPMENT OF COMPANIES BASED ON SOCIOECONOMIC MEASUREMENT STATISTICS / International Journal of Recent Technology and Engineering. 2019. T. 8. № 2. C. 4005-4012.

24. Sotnikova L.V., PolenovaS.N., MislavskayaN.A., PetrovA.M., BasovaM.M. SUSTAINABLE DEVELOPMENT, MACRO AND MICRO LEVEL: RUSSIAN AND FOREIGN MODEL / International Journal of Recent Technology and Engineering. 2019. T. 8. № 2. C. 4524-4532.

25. Kosolapova M.V., Muravitskaya N.K., TolmachevM.N., Melnikova L.A., PetrovA.M. TECHNOLOGY FOR SOLVING THE PROBLEMS RELATED TO THE IMPLEMENTATION OF THE CONCEPT OF PRESERVING CAPITAL IN ACCOUNTING AND STATISTICS / International Journal of Recent Technology and Engineering. 2019. T. 8. № 3. C. 789-792.

26. Kosolapova M.V., PetrovA.M., YshanovI.G., Muravitskaya N.K., NurmuhamedovaH.S. THE ECONOMIC SIGNIFICANCE OF STATISTICAL RESEARCH ACTIVITIES OF REPRESENTATIVE OFFICES OF COMPANIES ABROAD / International Journal of Innovative Technology and Exploring Engineering. 2019. T. 8. № 10. C. 27132722.

27. Petrov A.M., Yurasova I. O., Putihin Y.E., Poluleh M. V., Erohina V.N. ACCOUNTANT MODELING TECHNOLOGY AND STATISTICS IN THE CONTEXT OF THE NEW EDUCATIONAL CONCEPT / International Journal of Innovative Technology and Exploring Engineering. 2019. T. 8. № 12. C. 3214-3217.

28. Petrov A.M., Kiseleva N.P., KevorkovaZ.A., Melnikova L.A., YshanovI.G. PRESENT DEVELOPMENT PRACTICES FOR TAX, FINANCIAL AND STATISTICAL REPORTING IN THE RUSSIAN FEDERATION / International Journal of Innovative Technology and Exploring Engineering. 2019. T. 8. № 12. C. 3538-3542.

29. Karpova T.P., Petrov A.M., Antonova O. V. DIRECTIONS OF ACCOUNTING DEVELOPMENT IN THE CONDITIONS OF DIGITALIZATION / Journal of Advanced Research in Dynamical and Control Systems. 2018. T. 10. № 7 Special Issue. C. 117-125 
30. Lymar M.P., Kevorkova Z. A., Petrov A. M. THE CONVERGENCE OF NATIONAL AND INTERNATIONAL ACCOUNTING STANDARDS: CHINESE EXPERIENCE / International Journal of Civil Engineering and Technology. 2018. T. 9. № 13. C. $82-94$.

31. Бабаев Ю.А., Друцкая М. В., Кеворкова Ж. А., Листопад Е. Е., Петров А. М. БУХГАЛТЕРСКИЙ УЧЕТ, АНАЛИЗ И АУДИТ ВНЕШНЕЭКОНОМИЧЕСКОЙ ДЕЯТЕЛЬНОСТИ / Учебник для студентов обучающихся по специальности 080109 «Бухгалтерский учет, анализ и аудит» / под редакцией Ю.А. Бабаева. Москва, 2010.

32. Петров А.М., ПолоусЕ. А. ПОВЫШЕНИЕ ТРАНСПАРЕНТНОСТИ ПОКАЗАТЕЛЯ ДЕБИТОРСКОЙ ЗАДОЛЖЕННОСТИ В ОТЧЕТНОСТИ / Международный бухгалтерский учет. 2011. № 6 (156). С. 2-12.

33. Карпова Т.П., Петров А. М., Горбаткова Г. А., Самарина Л. Б., Дашкина Г. Г., Сидорова М. И., Сабанин Р. Л., Ситникова В.А., Листопад Е.Е. БУХГАЛТЕРСКИЙ УчЕТ В СФЕРЕ УСЛУГ / учебник дЛя студентов высшего профессионального образования, обучающихся по специальности 080109 «Бухгалтерский учет, анализ и аудит» / Под редакцией М.А. Вахрушиной; Москва, 2011. Сер. Читай

34. Петров А.М., МельниковаЛ.А. ФОРМИРОВАНИЕ ОТЧЕТНОСТИ В СООТВЕТСТВИИ С ТРЕБОВАНИЯМИ МСФО КАК ОБЪЕКТИВНАЯ НЕОБХОДИМОСТЬ НА СОВРЕМЕННОМ ЭТАПЕ РАЗВИТИЯ ЭКОНОМИКИ РФ / Проблемы современной экономики. 2017. № 2 (62). С. 105-107.

35. ТЕОРИЯ БУХГАЛТЕРСКОГО УЧЕТА / учебник / Ю.А.Бабаев, А. М.Петров; под ред. Ю.А.Бабаева. Москва, Проспект, 2011. (Изд. 5-е, перераб. и доп.)

Петров А.М. ОБЩЕСТВЕННОЕ ПИТАНИЕ 6 в 1: учетная политика, документооборот, калькулирование себестоимости, бухгалтерский учет, налоги, отчетность / А. М. Петров. Москва, 2011. Сер. Полное руководство бухгалтера 